\title{
Strategy-proofness and efficiency in labour production economy with unequal skills
}

\author{
Takashi Hayashi ${ }^{1}$
}

Received: 30 December 2014 / Revised: 13 December 2018 / Accepted: 14 December 2018 /

Published online: 31 January 2019

(c) The Author(s) 2019

\begin{abstract}
This paper characterizes the class of strategy-proof and efficient rules in a labour production economy in which technology is linear and individuals may have unequal labour productivities. As each individual's wage per hour is determined by his labour productivity under efficiency, an allocation rule reduces to a lump-sum transfer rule. We characterize how strategy-proofness and other axioms put restrictions on the class of lump-sum transfer rules, and we show that what we can do using lump-sum transfers is quite limited.
\end{abstract}

Keywords Unequal skills · Strategy-proofness · Efficiency

\section{Introduction}

This paper characterizes the class of strategy-proof and efficient rules in a production economy in which a consumption good is produced only from labour according to a linear technology and individuals may have unequal labour productivities.

As is shown by Pazner and Schmeidler (1974) that efficiency and fairness as absence of envy are incompatible when individuals have unequal skills, we have to make a choice between the two criteria. In this paper, we focus on efficiency. Under linear technology, efficiency alone implies that each individual's wage per hour is completely determined by his labour productivity, and any distributive concerns must be taken care of by lump-sum transfers. This paper characterizes how strategyproofness and other axioms put restrictions on such lump-sum transfers.

In contrary to other environments such as abstract domain and exchange economy, there is a class of strategy-proof and efficient rules. This is with affinity to the

Takashi Hayashi

Takashi.Hayashi@glasgow.ac.uk

1 Adam Smith Business School, University of Glasgow, West Quadrangle, Gilbert Scott Building, Glasgow G12 8QQ, UK 
result by Maniquet and Sprumont (1999), which considers a production economy with linear technology.

We show that lump-sum transfer to an individual has to be independent of his preference when we impose the strategy-proofness condition that one can never gain by misreporting his preference. We also consider a stronger strategy-proofness condition that one can never gain by misreporting his preference or hiding his skill. This implies that lump-sum transfer to an individual has to be non-decreasing in his skill level as well as independent of his preference.

The property that transfer to an individual has to be non-decreasing in his skill is already a stringent one, since it should be typically less skilled people who will need transfers if we insist on certain kind of fairness. This suggests that it is hard to save unskilled people even in the presence of skilled people. We show that under an additional axiom saying that having higher skill should not hurt anybody else the only possibility is a trivial case in which no redistribution is made.

The paper proceeds as follows. In the rest of this section, we illustrate how the current work is related to the existing literature. Section 2 presents the model and Sect. 3 presents the axioms. Section 4 presents the main results and Sect. 5 concludes.

\subsection{Related literature}

The most closely related paper is Maniquet and Sprumont (1999), which characterizes the class of strategy-proof and efficient allocation rules in a production economy with linear technology. Because of linear technology, price vector which supports efficient allocation is uniquely determined by technology alone, and the problem reduces to what lump-sum transfers should look like in order to be strategy-proof.

This paper is in the same sprit, as we assume linear technology and efficiency implies that an individual's wage per hour is determined by his labour productivity, and any distributive concerns are taken care of by lump-sum transfers.

The results obtained in linear production economies contrast with the classic results in other environments. In the abstract social choice setting, Gibbard (1973) and Satterthwaite (1975) show that a strategy-proof and efficient rule must be dictatorial. In economic environments, Hurwicz (1972), and Zhou (1991) and Serizawa (2002) show that strategy-proofness and efficiency lead to impossibility or dictatorship in exchange economies.

Pazner and Schmeidler (1974) demonstrate that the requirement of absence of envy is incompatible with efficiency of allocation when nobody. On the other hand, Varian (1974) proposes a notion of envy-freeness in which we adjust labour hours by asking how many hours one needs to work to make the same production as what is made by another.

Fleurbaey and Maniquet (1996) characterize an efficient allocation rule which satisfies Maskin monotonicity, an implementability condition and also an informational efficiency condition, and a weaker version of envy-freeness stating that it holds only for some fixed reference preference. Despite taking the weaker version of 
envy-freeness, they obtain that under additional axioms the set-valued solution must include the "trivial" solution which allows no redistribution.

We show, too, that it is hard to escape from the "trivial" solution under strategyproofness and efficiency. It is even more serious here, though, because we say we have to select the trivial solution, and any of the characterizing axioms says nothing explicitly about distributive concerns.

Fleurbaey and Maniquet (1999) propose an efficient resource allocation rule which satisfies skill monotonicity, an axiom stating that having higher skill hurts nobody. They provide a characterization of a rule satisfying the axiom, together with a distributional axiom stating that nobody should be made worse than the outcome of optimizing based on the lowest skill in the society and some other ones. Note that decentralizability conditions are not considered there, since as it is true in other environment as well decentralizability conditions and solidarity requirements are often in trade-offs, it is true in the current setting as well.

In the framework of fair social orderings, Fleurbaey and Maniquet (2006) characterize social orderings over allocations of labour and consumption based on the presumption that nobody is responsible for his skill level. In the framework of axiomatic bargaining, Yoshihara (2003) characterize a class of efficient allocation rules which allow people to be partially responsible for their skill levels.

Yamada and Yoshihara (2007); Yoshihara and Yamada (2010) provide conditions for allocation rules in production economies with unequal skills which are implementable in Nash equilibria in a type of mechanism in which individuals may exaggerate or hide their skills, while the mechanism is designed so that it does not happen in equilibrium. In contrary, we assume that one cannot exaggerate his skill while he can hide it, because under linear technology the planner can always detect exaggeration ex-post and even partially ex-ante, and because hiding is the only type of information manipulation which can be handled in the framework of strategyproofness (see "Discussions" after the definition of strategy-proofness).

\section{The model}

Consider a production economy with $n$ individuals, in which one consumption good is produced only from labour input. Assume that nobody holds any amount of consumption good in the outset and everybody has 1 unit of time which can be used for labour or leisure. We normalize the minimal possible level of consumption equal to zero as it is taken to be an implicit fixed factor.

Let $l_{i}$ denote individual $i$ 's labour hour for each $i=1, \ldots, n$, then the total amount of consumption good produced is given by

$$
\sum_{i=1}^{n} a_{i} l_{i},
$$

where $a_{i}>0$ denotes $i$ 's skill level. Let $a=\left(a_{1}, \ldots, a_{n}\right) \in \mathbb{R}_{++}^{n}$ denote a profile of skill levels, which is taken to be variable. 
Although one may think of a more general form of production function such as $f\left(\sum_{i=1}^{n} a_{i} l_{i}\right)$ or more generally $f\left(l_{1}, \ldots, l_{n}\right)$, we assume linear technology for two reasons. First, we view that most of ethical problems arising in the issue of unequal skills are already there in the simplest case of additive linear production, as far as the notion of individual skill remains clear and, thus, we restrict attention to it. ${ }^{1}$ Second, we focus on the class of technology in which the planner can always calculate an individual's observed productivity from his labour-output pair. This is critical for the planner to be able to detect exaggeration of reported skills. We will come to this point after the definition of strategy-proofness.

Each individual's consumption space is $[0,1] \times \mathbb{R}_{+}$. When $\left(l_{i}, c_{i}\right) \in[0,1] \times \mathbb{R}_{+}$is given to individual $i$, it means he works for $l_{i}$ units of time and consumes $c_{i}$ units of the consumption good, while he enjoys $1-l_{i}$ units of time for leisure.

Thus, an allocation $(l, c)=\left(l_{1}, \ldots, l_{n}, c_{1}, \ldots, c_{n}\right) \in[0,1]^{n} \times \mathbb{R}_{+}^{n}$ is said to be feasible if

$$
\sum_{i=1}^{n} c_{i} \leq \sum_{i=1}^{n} a_{i} l_{i} .
$$

We also use the notation $(l, c)=\left(\left(l_{1}, c_{1}\right), \ldots,\left(l_{n}, c_{n}\right)\right)$ in an interchangeable manner. Given $a=\left(a_{1}, \ldots, a_{n}\right) \in \mathbb{R}_{++}^{n}$, let $F(a)$ denote the set of feasible allocations under $a$.

Let $\mathcal{R}$ denote the set of preferences over $[0,1] \times \mathbb{R}_{+}$, which are complete and transitive, continuous, strictly convex, and strongly decreasing in labour hours and strongly increasing in consumptions.

For each individual $i$, given his preference $R_{i} \in \mathcal{R}$ and a compact convex set $B \subset[0,1] \times \mathbb{R}_{+}$, let $m\left(R_{i}, B\right)$ denote the maximal element in $B$ with respect to $R_{i}$, which is uniquely determined since $R_{i}$ is strictly convex.

A social choice function is a mapping $\varphi: \mathbb{R}_{++}^{n} \times \mathcal{R}^{n} \rightarrow[0,1]^{n} \times \mathbb{R}_{+}^{n}$ such that $\varphi(a, R) \in F(a)$ for all $(a, R) \in \mathbb{R}_{++}^{n} \times \mathcal{R}^{n}$, where $\varphi_{i}(a, R)$ denotes the allocation for $i=1, \ldots, n$. Also, given $(a, R)$ and $i$, let $l_{i}(a, R)$ denote the labour component of $\varphi_{i}(a, R)$ and $c_{i}(a, R)$ denote the consumption component of $\varphi_{i}(a, R)$.

It will be helpful to note here what we meant by "trivial" solution in the introduction. For each $i$, given $w_{i}>0$ and $t_{i} \geq-w_{i}$, let $B\left(w_{i}, t_{i}\right)$ denote $i$ 's budget set with slope $w_{i}$ and intercept $t_{i}$.

Definition $1 \varphi$ is said to be the trivial solution when it holds

$$
\varphi_{i}(a, R)=m\left(R_{i}, B\left(a_{i}, 0\right)\right)
$$

for all $(a, R) \in \mathbb{R}_{++}^{n} \times \mathcal{R}^{n}$ and $i=1, \ldots, n$.

\footnotetext{
${ }^{1}$ Further general form such as $f\left(l_{1}, \ldots, l_{n}\right)$ will allow complementarity between individuals' labour inputs. Then, it becomes a non-obvious question what we mean by an individual's own skill, even without decentralizability arguments.
} 


\section{Axioms}

\subsection{Strategy-proofness}

We present two versions of strategy-proofness. First one says that nobody can gain by misreporting his preference or hiding his skill. Note that one cannot exaggerate his own skill while he can hide his skill in a costless manner. For example, an individual who can produce 10 units per hour can pretend to be able only to produce 5 units per hour but cannot pretend to be able to produce 15 units per hour.

Strategy-proofness (SP): For all $i$, for all $\left(a_{-i}, R_{-i}\right) \in \mathbb{R}_{++}^{n-1} \times \mathcal{R}^{n-1}$ and for all $\left(a_{i}, R_{i}\right),\left(a_{i}^{\prime}, R_{i}^{\prime}\right) \in \mathbb{R}_{++} \times \mathcal{R}$ with $a_{i}^{\prime} \leq a_{i}$, it holds

$$
\varphi_{i}\left(\left(a_{i}, a_{-i}\right),\left(R_{i}, R_{-i}\right)\right) R_{i} \varphi_{i}\left(\left(a_{i}^{\prime}, a_{-i}\right),\left(R_{i}^{\prime}, R_{-i}\right)\right) \text {. }
$$

There are two reasons for assuming that an individual cannot exaggerate his skill. First is that because technology is additive and linear, and the planner can observe each individual's labour input and own production, exaggeration is always detected ex-post and one can be severely punished after detection. For example, if an individual reported that he can produce 15 units per hour but the planner observed that this individual produced 80 units in $8 \mathrm{~h}$, instead of 120 units in $8 \mathrm{~h}$, he concludes that the individual was able to produce only 10 units per hour and can detect the exaggeration. ${ }^{2}$ Again, this assumption requires that the planner can observe the truly spent labour hours as well as actual production, since otherwise one can for example pretend that a given production output can be achieved with shorter labour hours while the actual labour hours are longer, so as to disguise that his skill is higher. The second reason is a negative one: it is conceptually hard to allow actual possibility of exaggeration in the framework of strategy-proofness, and it requires a different framework. If an individual reports a fake information $\left(a_{i}^{\prime}, R_{i}^{\prime}\right)$ where reported skill $a_{i}^{\prime}$ is higher than true skill $a_{i}$, then the prescribed allocation $\varphi_{i}\left(\left(a_{i}^{\prime}, a_{-i}\right),\left(R_{i}^{\prime}, R_{-i}\right)\right)$ itself may not be feasible.

When skill levels are known we face a weaker constraint that nobody can gain by misreporting his preference. In the standard literature, it is called "strategy-proofness", but in order to emphasize that informational incompleteness is limited to preferences we call it preference strategy-proofness.

Preference strategy-proofness (PSP): For all $a \in \mathbb{R}_{++}^{n}$, for all $i$ and $R_{-i} \in \times \mathcal{R}^{n-1}$ and for all $R_{i}, R_{i}^{\prime} \in \mathcal{R}$, it holds

$$
\varphi_{i}\left(a,\left(R_{i}, R_{-i}\right)\right) R_{i} \varphi_{i}\left(a,\left(R_{i}^{\prime}, R_{-i}\right)\right) \text {. }
$$

\footnotetext{
2 It is possible to consider that the individual was indeed able to produce 15 units per hour and he reported this truthfully but he did not use full force in actual production, but in that case he can be punished for another reason.
} 


\subsection{Efficiency and envy-freeness}

Here, we state the axioms of allocative efficiency and equity.

Pareto efficiency (PE): For all $(a, R) \in \mathbb{R}_{++}^{n} \times \mathcal{R}^{n}$, there is no $\left(l^{\prime}, c^{\prime}\right) \in F(a)$ such that $\left(l_{i}^{\prime}, c_{i}^{\prime}\right) R_{i} \varphi_{i}(a, R)$ for all $i=1, \ldots, n$ and $\left(l_{i}^{\prime}, c_{i}^{\prime}\right) P_{i} \varphi_{i}(a, R)$ for at least one $i$.

Envy-freeness (EF): $\quad$ For all $(a, R) \in \mathbb{R}_{++}^{n} \times \mathcal{R}^{n}$ and for all $i, j=1, \ldots, n$, it holds $\varphi_{i}(a, R) R_{i} \varphi_{j}(a, R)$.

The following result is known due to Pazner and Schmeidler (1974).

\section{Proposition 1 There is no SCF which satisfies $P E$ and $E F^{3}$}

Thus, we have to make a choice between efficiency and envy-freeness in the outset. In this paper, we focus on efficient rules, implying that an individual's wage per hour must be completely determined by his labour productivity and any distributive concerns must be taken care of by lump-sum transfers. We study how strategyproofness and other axioms introduced below put restrictions on the class lump-sum transfer rules.

\subsection{Welfare lower bounds}

We introduce two axioms about welfare lower bounds. First one says that nobody should be made worse off than status quo, where the status quo is taken to be the point of no-work-no-pay.

Individual rationality (IR): $\quad$ For all $(a, R) \in \mathbb{R}_{++}^{n} \times \mathcal{R}^{n}$ and for all $i=1, \ldots, n$, it holds $\varphi_{i}(a, R) R_{i}(0,0)$.

Second one says that nobody should be made worse off than status quo, where the status quo point is such that everybody spends all his time on labour and gets paid according to the average skill.

Average skill lower bound (ASLB): $\quad$ For $\quad$ all $(a, R) \in \mathbb{R}_{++}^{n} \times \mathcal{R}^{n}$ and for all $i=1, \ldots, n$, it holds

$$
\varphi_{i}(a, R) R_{i}(1, \bar{a})
$$

where $\bar{a}=\frac{1}{n} \sum_{i=1}^{n} a_{i}$

\footnotetext{
3 Pazner and Schmeidler (1974) showed this using linear preferences, but their argument can be easily modified under strictly convex preferences.
} 


\subsection{Axiom on comparative property}

Finally, we introduce an axiom saying that when an individual's skill is higher it should not hurt anybody else.

Weak skill monotonicity (WSM): For all $i$, for all $a_{i}, a_{i}^{\prime} \in \mathbb{R}_{++}$with $a_{i}^{\prime} \leq a_{i}$, for all $a_{-i} \in \mathbb{R}_{++}^{n-1}$, and for all $R \in \mathcal{R}$, it holds

$$
\varphi_{j}\left(\left(a_{i}, a_{-i}\right), R\right) R_{j} \varphi_{j}\left(\left(a_{i}^{\prime}, a_{-i}\right), R\right)
$$

for all $j \neq i$.

By "weak", we mean the axiom does not cover the condition that the individual himself should not get hurt when his skill is higher, since it is covered by SP.

\section{Strategy-proof and efficient rules}

Here, we characterize the class of efficient allocation rules. Under efficiency, each individual's wage per hour has to be equal to his labour productivity, and argument reduces to how lump-sum transfers should be.

The following result is helpful.

Lemma 1 Assume PE. Then, $\varphi$ satisfies PSP if and only if for all $a \in \mathbb{R}_{++}^{n}$, for all $i$ and $R_{-i} \in \mathcal{R}^{n-1}$ and for all $R_{i}, R_{i}^{\prime} \in \mathcal{R}$ such that

$$
\left(l_{i}, c_{i}\right) P_{i}^{\prime} \varphi_{i}\left(a,\left(R_{i}, R_{-i}\right)\right) \Longrightarrow c_{i}-a_{i} l_{i}>c_{i}\left(a,\left(R_{i}, R_{-i}\right)\right)-a_{i} l_{i}\left(a,\left(R_{i}, R_{-i}\right)\right)
$$

for all $\left(l_{i}, c_{i}\right) \in[0,1] \times \mathbb{R}_{+}$, it holds $\varphi_{i}\left(a,\left(R_{i}^{\prime}, R_{-i}\right)\right)=\varphi_{i}\left(a,\left(R_{i}, R_{-i}\right)\right)$.

Proof "If" part: Suppose $\varphi_{i}\left(a,\left(R_{i}^{\prime}, R_{-i}\right)\right) P_{i} \varphi_{i}\left(a,\left(R_{i}, R_{-i}\right)\right)$. Then, we can take $R_{i}^{\prime \prime} \in \mathcal{R}$ such that

$$
\left(l_{i}, c_{i}\right) P_{i}^{\prime \prime} \varphi_{i}\left(a,\left(R_{i}, R_{-i}\right)\right) \Longrightarrow c_{i}-a_{i} l_{i}>c_{i}\left(a,\left(R_{i}, R_{-i}\right)\right)-a_{i} l_{i}\left(a,\left(R_{i}, R_{-i}\right)\right)
$$

for all $\left(l_{i}, c_{i}\right) \in[0,1] \times \mathbb{R}_{+}$and

$$
\left(l_{i}, c_{i}\right) P_{i}^{\prime \prime} \varphi_{i}\left(a,\left(R_{i}, R_{-i}\right)\right) \Longrightarrow c_{i}-a_{i} l_{i}>c_{i}\left(a,\left(R_{i}^{\prime}, R_{-i}\right)\right)-a_{i} l_{i}\left(a,\left(R_{i}^{\prime}, R_{-i}\right)\right)
$$

for all $\left(l_{i}, c_{i}\right) \in[0,1] \times \mathbb{R}_{+}$, and $\varphi_{i}\left(a,\left(R_{i}^{\prime}, R_{-i}\right)\right) P_{i}^{\prime \prime} \varphi_{i}\left(a,\left(R_{i}, R_{-i}\right)\right)$. Then, the condition implies $\varphi_{i}\left(a,\left(R_{i}^{\prime \prime}, R_{-i}\right)\right)=\varphi_{i}\left(a,\left(R_{i}, R_{-i}\right)\right)$ and $\varphi_{i}\left(a,\left(R_{i}^{\prime \prime}, R_{-i}\right)\right)=\varphi_{i}\left(a,\left(R_{i}^{\prime}, R_{-i}\right)\right)$, which is a contradiction.

"Only if" part: Suppose it holds

$$
\left(l_{i}, c_{i}\right) P_{i}^{\prime} \varphi_{i}\left(a,\left(R_{i}, R_{-i}\right)\right) \Longrightarrow c_{i}-a_{i} l_{i}>c_{i}\left(a,\left(R_{i}, R_{-i}\right)\right)-a_{i} l_{i}\left(a,\left(R_{i}, R_{-i}\right)\right)
$$

for all $\left(l_{i}, c_{i}\right) \in[0,1] \times \mathbb{R}_{+} \quad$ and $\varphi_{i}\left(a,\left(R_{i}^{\prime}, R_{-i}\right)\right) \neq \varphi_{i}\left(a,\left(R_{i}, R_{-i}\right)\right)$. By PE, $\varphi_{i}\left(a,\left(R_{i}, R_{-i}\right)\right)$ is supported by a line with slope $a_{i}$ and intercept $t_{i}$, and $\varphi_{i}\left(a,\left(R_{i}^{\prime}, R_{-i}\right)\right)$ 
is supported by a line with slope $a_{i}$ and intercept $t_{i}^{\prime}$, where $t_{i}^{\prime} \neq t_{i}$, because if $t_{i}^{\prime}=t_{i}$ the above condition is met only when $\varphi_{i}\left(a,\left(R_{i}^{\prime}, R_{-i}\right)\right)=\varphi_{i}\left(a,\left(R_{i}, R_{-i}\right)\right)$.

Without loss of generality, assume $t_{i}^{\prime}>t_{i}$. Then, we can take $R_{i}^{\prime \prime} \in \mathcal{R}$ such that its corresponding wealth-expansion path

$$
\left(l_{i}(t), c_{i}(t)\right)=m\left(R_{i}^{\prime \prime}, B\left(a_{i}, t\right)\right), \quad t \geq-a_{i}
$$

exhibits that $l_{i}(t)$ is non-increasing in $t$ and $c_{i}(t)$ is increasing in $t$, and

$$
\left(l_{i}\left(t_{i}\right), c_{i}\left(t_{i}\right)\right)=\varphi_{i}\left(a,\left(R_{i}, R_{-i}\right)\right),
$$

and $\varphi_{i}\left(a,\left(R_{i}^{\prime}, R_{-i}\right)\right) P_{i}^{\prime \prime} \varphi_{i}\left(a,\left(R_{i}, R_{-i}\right)\right)$.

Then, we have $\varphi_{i}\left(a,\left(R_{i}^{\prime \prime}, R_{-i}\right)\right)=\varphi_{i}\left(a,\left(R_{i}, R_{-i}\right)\right)$ because otherwise either of the two dominates the other, which leads to a violation of PSP.

Hence, we obtain $\varphi_{i}\left(a,\left(R_{i}^{\prime}, R_{-i}\right)\right) P_{i}^{\prime \prime} \varphi_{i}\left(a,\left(R_{i}^{\prime \prime}, R_{-i}\right)\right)$, which is a violation of PSP.

The result below states basically that under preference strategy-proofness any transfer to or from each individual has to be independent of his preference. Also, under strategy-proofness such transfer to each individual has to be non-decreasing in his skill.

For each $i$, given $w_{i}>0$ and $t_{i} \geq-w_{i}$, let $B\left(w_{i}, t_{i}\right)$ denote $i$ 's budget set with slope $w_{i}$ and intercept $t_{i}$.

Theorem $1 \varphi$ satisfies PSP and PE if and only if there exists a list of functions $t=\left(t_{1}, \ldots, t_{n}\right)$ with $t_{i}: \mathbb{R}_{++}^{n} \times \mathcal{R}^{n-1} \rightarrow \mathbb{R}$ and $t_{i}\left(a, R_{-i}\right)+a_{i} \geq 0$ for all $i$ and $\sum_{i=1}^{n} t_{i}\left(a, R_{-i}\right)=0$ for all $(a, R) \in \mathbb{R}_{++}^{n} \times \mathcal{R}^{n}$, such that

$$
\varphi_{i}(a, R)=m\left(R_{i}, B\left(a_{i}, t_{i}\left(a, R_{-i}\right)\right)\right)
$$

holds for all $(a, R) \in \mathbb{R}_{++}^{n} \times \mathcal{R}^{n}$ and $i=1, \ldots, n$.

Moreover, such $\varphi$ satisfies SP instead of PSP if and only if $t_{i}$ is non-decreasing in $a_{i}$ for each $i=1, \ldots, n$.

Proof It suffices to show the sufficiency of the axioms.

Pick any $(a, R) \in \mathbb{R}_{++}^{n} \times \mathcal{R}^{n}$, then by PE for each $i$ the allocation $\varphi_{i}(a, R)$ is supported by the straight line with slope $a_{i}$ and intercept denoted by $t_{i}(a, R)$. By construction, it holds $t_{i}(a, R)+a_{i} \geq 0$.

Since $c_{i}(a, R)=t_{i}(a, R)+a_{i} l_{i}(a, R)$ for each $i$ and from PE, we have

$$
\sum_{i=1}^{n} t_{i}(a, R)+\sum_{i=1}^{n} a_{i} l_{i}(a, R)=\sum_{i=1}^{n} c_{i}(a, R)=\sum_{i=1}^{n} a_{i} l_{i}(a, R),
$$

which implies 


$$
\sum_{i=1}^{n} t_{i}(a, R)=0 .
$$

To show that $t_{i}(a, R)$ is independent of $R_{i}$, suppose $t_{i}\left(a,\left(R_{i}^{\prime}, R_{-i}\right)\right)>t_{i}\left(a,\left(R_{i}, R_{-i}\right)\right)$. Then, we can take $R_{i}^{\prime \prime} \in \mathcal{R}$ such that

$$
\left(l_{i}, c_{i}\right) P_{i}^{\prime \prime} \varphi_{i}\left(a,\left(R_{i}, R_{-i}\right)\right) \Longrightarrow c_{i}-a_{i} l_{i}>c_{i}\left(a,\left(R_{i}, R_{-i}\right)\right)-a_{i} l_{i}\left(a,\left(R_{i}, R_{-i}\right)\right)
$$

for all $\left(l_{i}, c_{i}\right) \in[0,1] \times \mathbb{R}_{+}$, and $\varphi_{i}\left(a,\left(R_{i}^{\prime}, R_{-i}\right)\right) P_{i}^{\prime \prime} \varphi_{i}\left(a,\left(R_{i}, R_{-i}\right)\right)$.

By Lemma 1, we have $\varphi_{i}\left(a,\left(R_{i}^{\prime \prime}, R_{-i}\right)\right)=\varphi_{i}\left(a,\left(R_{i}, R_{-i}\right)\right)$.

Hence, we obtain $\varphi_{i}\left(a,\left(R_{i}^{\prime}, R_{-i}\right)\right) P_{i}^{\prime \prime} \varphi_{i}\left(a,\left(R_{i}^{\prime \prime}, R_{-i}\right)\right)$, which is a violation of PSP.

Now we show $t_{i}$ is non-decreasing in $a_{i}$ under SP. Suppose $t_{i}\left(a_{i}^{\prime}, a_{-i}, R_{-i}\right)<t_{i}\left(a_{i}, a_{-i}, R_{-i}\right)$ for $a_{i}^{\prime}>a_{i}$. Since $t_{i}$ is independent of $i$ 's preference, we can take $R_{i}$ such that

$$
\varphi_{i}\left(a_{i}, a_{-i}, R_{i}, R_{-i}\right) P_{i} \varphi_{i}\left(a_{i}^{\prime}, a_{-i}, R_{i}, R_{-i}\right),
$$

which is a violation of SP.

We consider further restrictions on the class of lump-sum transfer rules. Next result states that in the above class allocation rules adding the individual rationality axiom implies that the solution has to be trivial, in which there is no redistribution.

Theorem $2 \varphi$ satisfies PSP, PE and IR if and only if it holds

$$
\varphi_{i}(a, R)=m\left(R_{i}, B\left(a_{i}, 0\right)\right)
$$

for all $(a, R) \in \mathbb{R}_{++}^{n} \times \mathcal{R}^{n}$ and $i=1, \ldots, n$.

Proof It suffices to show the sufficiency of the axioms. Note that IR implies NC.

Pick any $i$, pick any $a \in \mathbb{R}_{++}^{n}, i$ and $R_{-i} \in \mathcal{R}^{n-1}$.

Suppose $t_{i}\left(a, R_{-i}\right)<0$. Since $t_{i}\left(a, R_{-i}\right)$ is independent of $R_{i}$ we can take $R_{i} \in \mathcal{R}$ such that $(0,0) P_{i} \varphi_{i}\left(a,\left(R_{i}, R_{-i}\right)\right)$, which is a violation of IR.

Thus, $t_{i}\left(a, R_{-i}\right) \geq 0$ holds for all $i$. Since $\sum_{i=1}^{n} t_{i}\left(a, R_{-i}\right)=0$, we have $t_{i}\left(a, R_{-i}\right)=0$ for all $i$.

Replacing IR by ASLB results in selecting a solution which equalizes potential incomes to be earned when they spend all their time on labour. This solution severely punishes the skilled people, though.

Theorem $3 \varphi$ satisfies PSP, PE and ASLB if and only if it holds

$$
\varphi_{i}(a, R)=m\left(R_{i}, B\left(a_{i}, \bar{a}-a_{i}\right)\right)
$$

for all $(a, R) \in \mathbb{R}_{++}^{n} \times \mathcal{R}^{n}$ and $i=1, \ldots, n$, where $\bar{a}=\frac{1}{n} \sum_{i=1}^{n} a_{i}$.

Proof It suffices to show the sufficiency of the axioms. Note that ASLB implies NC. Pick any $i$, pick any $a \in \mathbb{R}_{++}^{n}, i$ and $R_{-i} \in \mathcal{R}^{n-1}$. 
Suppose $t_{i}\left(a, R_{-i}\right)<\bar{a}-a_{i}$. Since $t_{i}\left(a, R_{-i}\right)$ is independent of $R_{i}$ we can take $R_{i} \in \mathcal{R}$ such that $(1, \bar{a}) P_{i} \varphi_{i}\left(a,\left(R_{i}, R_{-i}\right)\right)$, which is a violation of ASLD.

Hence, $t_{i}\left(a, R_{-i}\right) \geq \bar{a}-a_{i}$ holds for all $i$. Since $\sum_{i=1}^{n} t_{i}\left(a, R_{-i}\right)=0$ follows from feasibility, we have $t_{i}\left(a, R_{-i}\right)=\bar{a}-a_{i}$ for all $i$.

Example 1 Here is a class of rules satisfying SP and PE and includes the above solution as the endpoint: given $\beta \in[0,1]$, the allocation rule is defined by

$$
\varphi_{i}(a, R)=m\left(R_{i}, B\left(a_{i}, \beta\left(\bar{a}-a_{i}\right)\right)\right)
$$

for all $(a, R) \in \mathbb{R}_{++}^{n} \times \mathcal{R}^{n}$ and $i=1, \ldots, n$, where $\bar{a}=\frac{1}{n} \sum_{i=1}^{n} a_{i}$. Notice that when $\beta=0$ it reduces to the trivial solution and when $\beta=1$ it reduces to the solution to equalize potential incomes.

Note, however, that it does not satisfy SP except when $\beta=0$, since it in general hurts an individual when he has higher skill.

Now let us not insist on either of IR or ASLB and return to the class of allocation rules as characterized in Theorem 1. It is already a stringent property, however, that transfer to an individual has to be non-decreasing in his skill under SP, because the purpose of transfer is typically to help less skilled people. This suggests that it is hard to save unskilled people even in the presence of skilled people. Weak Skill Monotonicity is an axiom stating that if one has more skill it should not hurt anybody else, while the requirement that it should not hurt himself is covered by SP. The result below states that when we strengthen PSP to SP and add WSM the lump-sum transfers must be zero, which is the case of the trivial solution.

Theorem $4 \varphi$ satisfies SP, PE and WSM if and only if it holds

$$
\varphi_{i}(a, R)=m\left(R_{i}, B\left(a_{i}, 0\right)\right),
$$

for all $(a, R) \in \mathbb{R}_{++}^{n} \times \mathcal{R}^{n}$ and $i=1, \ldots, n$.

Proof It suffices to show the sufficiency of the axioms.

Pick any $a, a^{\prime} \in \mathbb{R}_{++}^{n}$ with $a^{\prime} \geq a$ and pick arbitrary $R \in \mathcal{R}^{n}$.

Suppose $t_{i}\left(a_{i}^{\prime}, a_{-i}, R_{-i}\right)<t_{i}\left(a, R_{-i}\right)$. Since $R \in \mathcal{R}^{n}$ was arbitrary and $t_{i}$ is independent of $R_{i}$, we can take it so that $m\left(R_{i}, B\left(a_{i}, t_{i}\left(a_{i}, a_{-i}, R_{-i}\right)\right)\right) P_{i} m\left(R_{i}, B\left(a_{i}^{\prime}, t_{i}\left(a_{i}^{\prime}, a_{-i}, R_{-i}\right)\right)\right)$, that is, $\varphi_{i}\left(a_{i}, a_{-i}, R\right) P_{i} \varphi_{i}\left(a_{i}^{\prime}, a_{-i}, R\right)$, which is a violation of SP. Hence $t_{i}\left(a_{i}^{\prime}, a_{-i}, R_{-i}\right) \geq t_{i}\left(a, R_{-i}\right)$.

Suppose $t_{j}\left(a_{i}^{\prime}, a_{-i}, R_{-j}\right)<t_{j}\left(a, R_{-j}\right)$ for some $j \neq i$. Since $R \in \mathcal{R}^{n}$ was arbitrary and $t_{j}$ is independent of $R_{j}$, we can take it so that

$$
m\left(R_{j}, B\left(a_{j}, t_{j}\left(a_{i}, a_{-i}, R_{-j}\right)\right)\right) P_{j} m\left(R_{j}, B\left(a_{i}^{\prime}, t_{j}\left(a_{i}^{\prime}, a_{-i}, R_{-j}\right)\right)\right),
$$

that is, $\varphi_{j}\left(a_{i}, a_{-i}, R\right) P_{j} \varphi_{j}\left(a_{i}^{\prime}, a_{-i}, R\right)$, which is a violation of WSM. Hence $t_{j}\left(a_{i}^{\prime}, a_{-i}, R_{-j}\right) \geq t_{j}\left(a, R_{-j}\right)$ for all $j \neq i$. 
Since $\quad \sum_{j=1}^{n} t_{j}\left(a_{i}^{\prime}, a_{-i}, R_{-j}\right)=\sum_{j=1}^{n} t_{j}\left(a_{i}, a_{-i}, R_{-j}\right)=0, \quad$ we $\quad$ obtain $t_{j}\left(a_{i}^{\prime}, a_{-i}, R_{-j}\right)=t_{j}\left(a, R_{-j}\right)$ for all $j=1, \ldots, n$.

By repeating the above argument, we obtain $t_{j}\left(a^{\prime}, R_{-j}\right)=t_{j}\left(a, R_{-j}\right)$ for all $j=1, \ldots, n$.

Pick any $a, a^{\prime} \in \mathbb{R}_{++}^{n}$, and let $a \wedge a^{\prime}$ be the vector defined by $\left(a \wedge a^{\prime}\right)_{i}=\min \left\{a_{i}, a_{i}^{\prime}\right\}$ for each $i$. Then, since $t_{j}\left(a, R_{-j}\right)=t_{j}\left(a \wedge a^{\prime}, R_{-j}\right)$ and $t_{j}\left(a^{\prime}, R_{-j}\right)=t_{j}\left(a \wedge a^{\prime}, R_{-j}\right)$ we obtain $t_{j}\left(a^{\prime}, R_{-j}\right)=t_{j}\left(a, R_{-j}\right)$ for all $j=1, \ldots, n$. Hence, $t_{j}$ is independent of $a$ for all $j=1, \ldots, n$, and we write it by $t_{j}\left(R_{-j}\right)$.

Now we show $t_{j}\left(R_{-j}\right) \geq 0$. Suppose $t_{j}\left(R_{-j}\right)<0$ for some $j$. Then, there exists $a \in \mathbb{R}_{++}^{n}$ such that $t_{j}\left(R_{-j}\right)+a_{j}<0$, which violates feasibility of allocation. Hence $t_{j}\left(R_{-j}\right) \geq 0$ for all $j$.

Since $\sum_{j=1}^{n} t_{j}\left(R_{-j}\right)=0$, we obtain $t_{j}\left(R_{-j}\right)=0$ for all $j$.

None of the above axioms says anything explicit about distributive justice, but the conjunction of them allows only the trivial case in which no redistribution is allowed.

\section{Concluding remarks}

We have characterized the class of strategy-proof and efficient rules in a labour production economy in which technology is linear and individuals may have unequal labour productivity. As each individual's wage per hour is determined by his labour productivity under efficiency, an allocation rule reduces to a lump-sum transfer rule.

We have shown that lump-sum transfer to an individual has to be independent of his preference when we impose the strategy-proofness condition that one can never gain by misreporting his preference. We also consider a stronger strategy-proofness condition that one can never gain by misreporting his preference or hiding his skill. The latter implies that lump-sum transfer to an individual has to be non-decreasing in his skill level as well as independent of his preference.

We have shown that under an additional axiom saying that having higher skill should not hurt anybody else the only possibility is the trivial case in which no redistribution is made.

This suggests that what we can do using lump-sum transfers under the presumption of efficiency is quite limited, and it may be worth thinking of using distortionary wages/taxes as well as lump-sum transfers to accommodate with distributive concerns.

Acknowledgements I thank the referee for detailed comments and suggestions, Editor Takashi Ui for helpful comments, and seminar participants at Hitotsubashi, Kobe, Kyoto and Osaka for helpful feedbacks.

Open Access This article is licensed under a Creative Commons Attribution 4.0 International License, which permits use, sharing, adaptation, distribution and reproduction in any medium or format, as long as you give appropriate credit to the original author(s) and the source, provide a link to the Creative Commons licence, and indicate if changes were made. The images or other third party material in this article are included in the article's Creative Commons licence, unless indicated otherwise in a credit line to the material. If material is not included in the article's Creative Commons licence and your intended use is not permitted by statutory regulation or exceeds the permitted use, you will need to obtain permission 
directly from the copyright holder. To view a copy of this licence, visit http://creativecommons.org/licen ses/by/4.0/.

\section{References}

Fleurbaey, M., \& Maniquet, F. (1996). Fair allocation with unequal production skills: The no envy approach to compensation. Mathematical Social Sciences, 32(1), 71-93.

Fleurbaey, M., \& Maniquet, F. (1999). Cooperative production with unequal skills: The solidarity approach to compensation. Social Choice and welfare, 16(4), 569-583.

Fleurbaey, M., \& Maniquet, F. (2006). Fair income tax. Review of Economic Studies, 73(1), 55-83.

Gibbard, A. (1973). Manipulation of voting schemes: A general result. Econometrica, 41, 587-601.

Hurwicz, L. (1972). On informationally decentralized systems. In: R. Radner., C.B. McGuire (Eds.), Decision and organization: A volume in Honor of J. Marschak(pp. 297-336) North-Holland: Amsterdam.

Maniquet, F., \& Sprumont, Y. (1999). Efficient strategy-proof allocation functions in linear production economies. Economic Theory, 14(3), 583-595.

Pazner, E. A., \& Schmeidler, D. (1974). A difficulty in the concept of fairness. Review of Economic Studies, 41(3), 441-443.

Satterthwaite, M. A. (1975). Strategy-proofness and Arrow's conditions: Existence and correspondence theorems for voting procedures and social welfare functions. Journal of Economic Theory, 10(2), $187-217$.

Serizawa, S. (2002). Inefficiency of strategy-proof rules for pure exchange economies. Journal of Economic Theory, 106(2), 219-241.

Varian, H. R. (1974). Equity, envy, and efficiency. Journal of Economic Theory, 9(1), 63-91.

Yamada, A., \& Yoshihara, N. (2007). Triple implementation by sharing mechanisms in production economies with unequal labor skills. International Journal of Game Theory, 36(1), 85-106.

Yoshihara, N., \& Yamada, A. (2010). Nash implementation in production economies with unequal skills: A complete characterization. Social Choice and Welfare. https://doi.org/10.1007/s00355-019-01174 -w.

Yoshihara, N. (2003). Characterizations of bargaining solutions in production economies with unequal skills. Journal of Economic Theory, 108(2), 256-285.

Zhou, L. (1991). Inefficiency of strategy-proof allocation mechanisms in pure exchange economies. Social Choice and Welfare, 8(3), 247-254.

Publisher's Note Springer Nature remains neutral with regard to jurisdictional claims in published maps and institutional affiliations. 